revista ANTHROPOLÓGICAS

Ano 25, 32(2): 168-192, 2021

doi.org/10.51359/2525-5223.2021.252867

\title{
'Bem-feitinho': produção artesanal e afirmação cultural de mulheres indígenas em Boa Vista/RR
}

Nathalia Bianca da Silva Martes ${ }^{\mathrm{a}}$

Olendina de Carvalho Cavalcante ${ }^{\mathrm{b}}$

Resumo: $\mathrm{O}$ presente trabalho resulta de uma pesquisa feita com mulheres indígenas, membros da Associação Cultural Indígena Kapói, que saíram de suas comunidades de origem, na Guiana, e hoje residem no contexto urbano da cidade de Boa Vista, capital de Roraima, onde utilizam o artesanato indígena como instrumento de geração de renda e afirmação cultural. A produção de artefatos põe em relevo técnicas e conhecimentos apreendidos na vida comunitária e critérios do fazer bem-feito, comuns a povos indígenas das terras baixas sul-americanas, e necessárias ao novo universo social que valoriza um produto esteticamente bem-feito para venda.

Palavras-chave: Artesanato indígena, Mulheres indígenas, Contexto urbano, Afirmação cultural.

Este trabalho busca refletir sobre o significado de artefatos indígenas na afirmação cultural e na estratégia de renda para as mulheres membros da Associação Cultural Indígena Kapói ${ }^{1}$. Essa associação, criada em 2003 por três indígenas, estimula a produção de práticas culturais na cidade e luta pelo reconhecimento da presença indígena nesse espaço; a maioria dos associados é formada por mulheres que passaram por experiências de deslocamentos de suas comunidades de origem, na Republica Cooperativa da Guiana, para a cidade de Boa

a Mestre em Antropologia Social (UFRR). Email: nathalia_martes@hotmail.com.

b Doutora em Antropologia Social (UNICAMP). Professora associada do Mestrado de Antropologia Social (UFRR). Email: dcavalcante@hotmail.com. 
Vista, capital de Roraima; no universo urbano, experimentaram inúmeras situações que são vistas como desafios e barreiras associados ao gênero, raça e etnia, tais como os trabalhos temporários, empregos mal remuneradas, dificuldade com a língua portuguesa e o preconceito contra a população indígena que vive na cidade. Uma vez na cidade, elas tiveram que aprender a lidar com um novo universo social, sem, no entanto, abandonar práticas culturais comuns à vida nas comunidades, dando origem a um processo de mão dupla, em que se percebe a presença da aldeia na cidade e da cidade na aldeia, como mostrou Lasmar (2005), para o caso do rio Negro, em sua obra De volta ao lago de leite: gênero e transformação no Alto Rio Negro. Para essa autora, a comunidade e a cidade representam, para os índios, modos distintos de existência que organizam modos de vida diversos, no entanto, o deslocamento de indígenas para a cidade é um fato que está a cada dia se tornando mais intenso e enfatiza esse ponto importante: "De todo modo, se o processo de deslocamento para a cidade é um fato, isso não subtrai da vida em comunidade o papel de referência simbólica" (Lasmar 2005:145).

Não obstante aos desafios presentes no contexto urbano, as mulheres indígenas procuram tornar sua participação cada dia mais legitima na sociedade nacional e, por meio da produção de artefatos, elas procuram ainda destacar a cultura de seu povo. As mulheres da Kapói buscam um lugar para seus trabalhos, que além de evidenciar a própria cultura, busca ainda sua valorização enquanto mulher indígena. Nesse sentido, corroborando com Keller:

"O artesanato é aqui concebido como um fenômeno heterogêneo, complexo e diversificado. Sua importância vem da capacidade deste segmento de promover a inclusão social por meio da geração de renda e ocupação e de resgatar valores culturais e regionais" (Keller 2014:324).

No caso em estudo, as mulheres indígenas encontram, na produção de artefatos, uma oportunidade para conseguir uma renda extra e 
contribuir para a manutenção da família, além da satisfação encontrada no 'saber fazer'. Para elas a produção artesanal de objetos culturais vai muito além da questão da arte tal como concebida em termos teóricos, é um saber que vem de gerações e que emana ancestralidade: fiar o algodão, fazer rede, fazer colares, cocares, cestos e outras tantas peças, vem de um conhecimento adquirido no seio da comunidade, e a continuidade dessa prática constitui, ao mesmo tempo, a transmissão de saberes adquiridos desde a infância.

Como observa Aroni (2010), apreende-se muitos sobre pessoas, povos e contextos sociais ao observar aquilo que elas produzem, nos quais os artefatos, objetos fabricados artesanalmente, assumem uma posição relevante. A produção de artefatos enquanto artesanato no âmbito da associação Kapói, reproduz esse universo de aprendizado coletivo, tal como na comunidade, como mostraremos.

Um breve passeio pela literatura etnográfica mostra a enorme diversidade que enfeixa a noção de artefatos indígenas. A interessante reflexão de Lagrou (2010) chama atenção para o fato de os povos indígenas não partilharem da noção de arte tal qual definida no 'mundo ocidental', mas isso não significa que estes não tenham seus próprios critérios de beleza e estética na produção de artefatos. Os objetos produzidos por estes povos são imbrincados em complexas redes de interação, que abrange as relações com o mundo social e a com a natureza, com significados que compõem a perspectiva de mundo dos povos indígenas.

“[...] muitos artefatos e grafismos que marcam o estilo de diferentes grupos indígenas são materializações densas de complexas redes de interações que supõem conjuntos de significados, ou, como diria Gell, que levam a abduções, inferências com relação a intenções e ações de outros agentes. São objetos que condensam ações, relações, emoções e sentidos, porque é através dos artefatos que as pessoas agem, se relacionam, se produzem e existem no mundo" (Lagrou 2010:2).

Ainda de acordo com a autora, para os indígenas não existe diferença entre artefato e arte, onde o primeiro é produzido para uso 
cotidiano, e o segundo para ser contemplado. De tal modo o artefato indígena é produzido para possuir uma função e um significado no seio da comunidade, além de dar continuidade a um conhecimento considerado ancestral; sua apreciação ou contemplação enquanto arte se torna apenas um fator de coexistência entre esses dois mundos distintos. Arte e artefato se relacionam e se sobrepõem um ao outro, onde "[...] funcionalidade e contemplação se tornam inseparáveis, resultando na eficácia estética da capacidade de uma imagem agir sobre e, deste modo, criar e transformar o mundo [...]" (Lagrou 2010:20).

Todavia, a sociedade nacional, que em termos conceituais opera por oposição, e não raro, compreende arte e artesanato em oposição, diferentemente dos povos indígenas. Goldstein, observa que a sociedade nacional percebe esses dois quesitos como conceitos separados num "sistema das artes" onde "as criações populares e indígenas costumam ser ignoradas ou relegadas a um segundo plano. Separar o artesanato da arte é uma das estratégias de hierarquização desse sistema" (2014:03). Assim, é relevante notar que o conceito de arte é totalmente subjetivo, tornando-se mais uma questão de conceito do que fenômeno.

$\mathrm{O}$ artesanato também perpassa a fronteira da arte, e com ela se entrelaça, podendo ser vista a partir de diversas tipologias. Como destaca Lemos (2011), há o artesanato de reciclagem, o tradicional, de referência cultural, contemporâneo conceitual e por último o termo que mais se adéqua a esse estudo, o artesanato indígena.

$O$ valor estético do artefato indígena constitui-se, ainda, no quesito perfectibilidade do objeto produzido. Foi observado, no trabalho de campo, que na produção dos artefatos, todo cuidado e atenção são necessárias para não ocorrer qualquer erro que possa arruinar a peça em processo de fabricação. Além da atenção minuciosa e da paciência necessária ao processo de fabricação das peças, é necessário também a destreza e delicadeza no manejo das peças, e assim fazer 'bem-feitinho' cada peça. Nesse aspecto, o saber indígena é fundamental para o emprego das técnicas ancestrais, aprendidas desde a infância, am- 
pliando-se na puberdade por questões matrimoniais ${ }^{2}$, e na velhice se tornam fonte de especialização e refinamento, e assim "[...] Como objetos uteis, eles são consumidos. E como bens simbólicos são dotados de significados" (Ribeiro 1998:135). Esse saber é resultado de uma transmissão social de conhecimento entre gerações, feito de forma sexualmente diferenciada, com a visualização de modelos, técnicas e reprodução continuada. Dessa forma, a reprodução de artefatos que fazem parte de um conhecimento ancestral demonstra o respeito às técnicas de produção e a cultura de cada povo, e uma vez fora de suas comunidades de origem, os indigenas 'reestruturam' esses saberes como forma de sobrevivência (Velthen 2014).

As interlocutoras desse trabalho são mulheres indígenas Wapichana e Macuxi, que no processo de deslocamento de suas comunidades de origem, na Guiana, para a cidade de Boa Vista, motivadas por diversos fatores, como: trabalho assalariado, acesso à educação, assistência médica e melhores condições de vida, acabaram optando por permanecer com suas famílias na cidade, mas sempre mantendo os laços com suas comunidades de origem, visitando-as periodicamente.

\section{$\mathrm{O}$ artesanato indígena como instrumento de afirmação cultural}

A produção de artefatos enquanto artesanato é uma das grandes manifestações de cultura indígena na cidade de Boa Vista, juntamente com diversas modalidades de performances - dança parixara, corais, bandas musicais, rituais de pajelança, entre outros - realizados por representantes de diferentes povos que habitam tanto a região de campos e serras como a região de floresta. Sua comercialização é realizada tanto em Boa Vista, como em comunidades próximas da cidade, centros culturais e artesanais, associações indígenas, entre outros; além de legitimar a presença da cultura indígena no universo urbano, sua produção e comercialização são fonte ou complemento de renda para muitas famílias indígenas, como já pontuamos.

Os povos indígenas que vivem na capital roraimense possuem um rico repertorio cultural, e dessa forma, tentam conciliar o saber ances- 
tral com o modo de vida urbano. Segundo Florissi \& Fioretti (2012), a cidade de Boa Vista, assim como outras cidades, é um lugar de grande interação social e cultural, com perfil multicultural, que concentra a produção e consumo de bens culturais, e assim, o artesanato indígena aparece como uma das várias manifestações materiais de identidade e afirmação cultural em Boa Vista, onde, de acordo com os autores, os processos culturais se 'constroem'.

O apreço por artefatos indígenas se dá desde a chegada dos primeiros viajantes às Américas, que coletavam objetos para levar a Europa e depositar em instituições públicas onde se tornavam fontes de informação. Ribeiro \& Velthem (1992) destacam que o colecionismo de artefatos indígenas do século XIX tinha por objetivo evitar a perda da cultura de povos que estavam fadados à extinção naquela época. No mesmo caminho, Porto Alegre (1998) ressalta que o olhar colecionador de artefatos indígenas no Brasil se dá por meio dos viajantes que aqui estiveram durante o século XIX. O processo de coleta de artefatos para coleções etnográficas era uma missão especial para a etnografia, pois achava-se necessário recolher o maior número de documentos culturais vivos de povos considerados a beira da extinção. Essa coleta advém do propósito de 'salvar' as culturas do suposto processo de desaparecimento, depositando-a em museus. Grande parte de artefatos indígenas brasileiros e sul-americanas recolhidos ao longo do século XIX e início do século XX encontram-se em museus da Europa.

Objetos de uso cotidiano e exemplos de expressões culturais nas comunidades, tais artefatos acabam por se tornar objetos exóticos na cidade, como podemos observar em Boa Vista. Adornos, utensílios domésticos, armas de caça, entre outros tantos artefatos, se tornam objetos de decoração, peças de exibição e estudos em museus e/ou universidades, além de objetos turísticos, para registrar através destes o modo de vida indígena. E pelo fato de serem confeccionados de forma manual, a sociedade nacional tende a caracterizar tais artefatos como objetos artesanais, como já apontamos. 
"Paralelamente, os artefatos indígenas são invariavelmente apreciados pelo senso comum enquanto 'artesanato', termo institucionalizado pelos que os negociam em lojas de suvenir ou de artigos para decoração. Essa classificação aponta para a ideia de que as artes indígenas seriam anônimas e, assim, desprovidas de autoria individual. [...] A outra face dessa moeda é constituída pela aura do exotismo atribuída as produções materiais e imateriais indígenas, e aos próprios índios" (Velthem 2010:58).

Atualmente é comum, entre os próprios indígenas, principalmente os que vivem na cidade, se referirem a esses artefatos como artesanato, mas num sentido próprio, como um objeto que evidencia ou representa uma cultura, que expressa a maestria de diversos povos, e como objeto de afirmação indígena no universo urbano.

"O artesanato indígena é resultado dos trabalhos produzidos no seio de comunidades e etnias indígenas, onde se identificam o valor de uso, a relação social e cultural da comunidade. Os produtos, em sua maioria, são resultantes de trabalhos coletivos, incorporados ao cotidiano da vida tribal" (Lemos 2011:44).

A produção de artefatos para venda na cidade, para além da afirmação cultural indígena, aponta para uma relevância econômica, pois, em muitos casos, tem contribuído para o sustento das famílias que não dispõem de uma renda mensal. Um exemplo já bem conhecido é a venda de panelas de barro produzido pelas mulheres Macuxi, da aldeia Raposa I, em que "a venda das panelas possibilitou, para algumas mulheres, o acesso a uma renda, contribuindo também para elevar as suas autoconfianças" (Cavalcante 2013:104). Tal fato também é notado entre as mulheres da Kapói, como narra Dona Selestina:

Eu gosto, tô ganhando de 5, 10, 20 reais, por aí né, ajuda muito. É bom quando a gente faz muito artesanato e aí vende [...]. É bom fazer artesanato. Um dia a gente fez muito e ganhou $\mathrm{R} \$ 600,00$. Eu falei para Delci, $[. .$.$] assim dá comprar umas coisas pra neném, quando$ tu faz 10 colar, já é R\$100,00 né? (Selestina).

O artesanato indígena, além de evidenciar uma manifestação cultural, se tornou uma alternativa de trabalho e renda para as indígenas 
que vivem na cidade. $\mathrm{O}$ relato de Dona Maria, reforça esse aspecto da autonomia advinda da venda de artesanato: "Aí eu fui vender meu artesanato, gostei de ganhar meu dinheirinho de lá, né? [...] assim, em casa dá pra ajudar, né?".

Na cidade de Boa Vista, atualmente, a produção artesanal indígena, empreendido em cunho econômico, causa grande fascínio a turistas pelo caráter 'exótico' das peças, onde recorrem a centros artesanais na cidade para adquirir uma peça originalmente produzida por indígenas. Se na comunidade são bens uteis de uso cotidiano e/ ou ritual, na cidade são bastante apreciados, e vale ressaltar que nos centros turísticos, ou mesmo nos eventos culturais, artísticos e acadêmicos, as peças indígenas sempre encontram espaço para comercialização. As belas cestarias e colares Ye`kuana, a cestaria Waimiri Atroari e as panelas de barro Macuxi, são muito valorizadas pelos consumidores locais e por turistas, vendidas a preços justos, pois trazem o selo indígena, sempre com preços mais altos que as peças não indígenas.

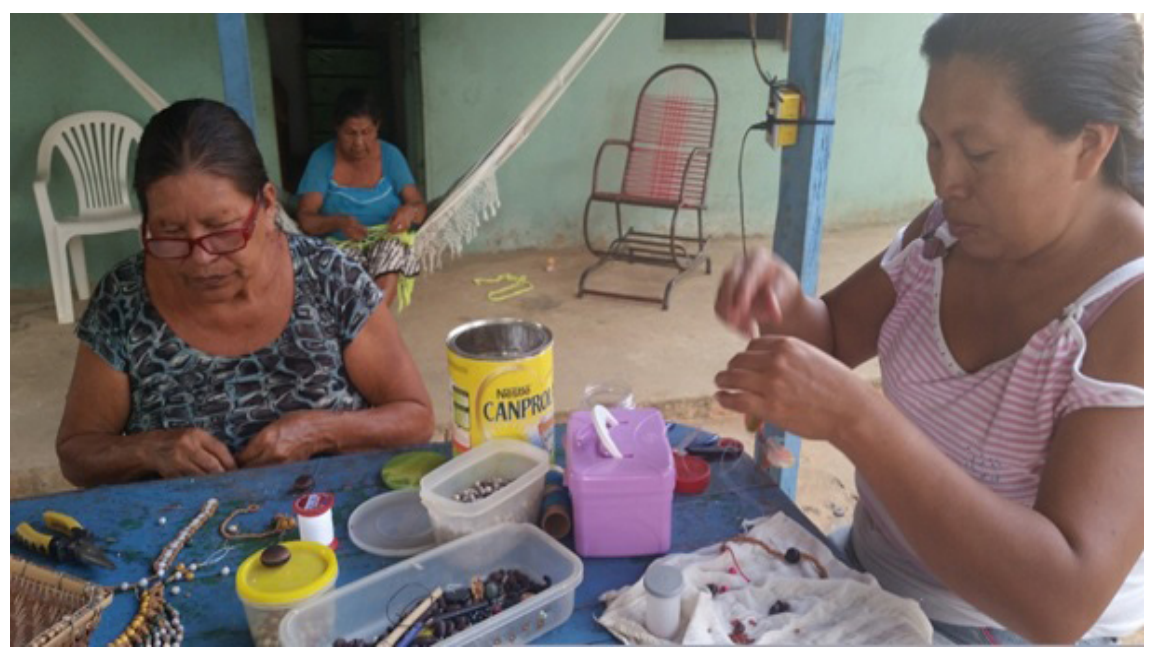

Figura - 1: Mulheres confeccionando o artesanato indígena.

Fonte: Martes 2015. 
Geralmente a maior fonte e complementação de renda de algumas famílias indígenas no estado está na comercialização de artefatos, com grande variedade estética, repercutindo assim sua cultura. As poucas e mal remuneradas oportunidades de trabalho levaram as mulheres indígenas a encontrar na produção artesanal um complemento de renda para o sustento da família no contexto urbano. Para Delci, "é melhor fazer artesanato porque as pessoas vêm aqui atrás, pra comprar, assim eu consigo dinheiro pra comprar coisas pros meninos".

É no âmbito da associação Kapói que as mulheres se articulam com atividades voltadas ao aprendizado da confecção de peças para serem vendidas. Os associados aprendem com os que já dominam as técnicas de confecção de uma peça e a relação dos indígenas dentro desse espaço favorece a transferência de conhecimentos e técnicas; assim, tanto adultos quanto crianças aprendem as técnicas de produção de artefatos. Dentre as peças confeccionadas se encontram:

- Cestos

- Abanadores

- Tipitis

- Braçadeiras

- Cocares

- Adornos (colares, pulseiras, brincos e enfeites de cabelo)

- Esculturas de madeira

- Saias de fibra

- Chocalhos

Os associados dão importância à coleta de matérias-primas originais para confecção artesanal; coletam sementes, palhas e penas em diversos locais, tanto na cidade quanto nas comunidades próximas, e, também, nas comunidades de origem, por ocasião de visitas, principalmente sementes e palhas que são mais difíceis de coletar na cidade: "palha de buriti, tucumã, é só os homens que vão poder tirar lá de cima, aí óleo de buriti a gente tira por aqui”, ressalta Delci.

Dona Selestina afirma que alguns materiais são comprados de outros povos, como por exemplo as penas de pássaros e alguns tipos de 176 
sementes que ela compra dos indígenas Wai-wai, da região sul do estado. Eles se comunicam por telefone quando há material disponível para a associação. Quando esse comércio não é possível, os associados realizam coleta nas margens do rio Branco, nas comunidades indígenas próximas à cidade como Tabalascada e Moskow (Wapichana), em outros municípios tais como Caracaraí, Alto Alegre, ou ainda em comunidades rurais, como bem destacam as falas a seguir:

A gente vai pra Vista Alegre pra ajuntar semente, a gente trabalha pra longe assim, ajuntando semente. Quando a gente vai ali no rio Branco, qualquer semente que a gente acha traz pra ver como é né, se é boa ou não. As penas a gente compra. (Selestina).

Semente, as vezes eu vou lá na mata ajuntar. A gente ajunta por aí, semente em qualquer lugar que a gente anda, a gente ajunta, é assim que a gente faz, pega e fura com furadeira. Lá no interior, as vezes que eles (parentes) matam, assim, pra comer né, aí eu falo: cadê aquelas penas? Aí eles guardam pra mim, onde a gente acha pena, a gente não estraga não. (Maria).

Em relação às sementes, Delci afirma que é melhor procurar semente na Guiana e assim justifica: "porque lá na minha comunidade tem muito e aqui semente tem que comprar e também é caro". As sementes coletas são socializadas no grupo, Dona Vanda, sempre que possível, envia sementes para Dona Selestina distribuir entre as mulheres e assim confeccionar o artesanato para comercializar. Essa socialização ocorre tanto para as matérias primas como também com outras práticas culturais, cujo objetivo é fortalecer as relações de confiança do grupo, formado por pessoas de diferentes povos, com distintas experiências em relação ao mundo urbano. Alguns chegaram a Boa Vista na década de 1980, outros nas décadas de 1990 e 2000. Sobre essas relações ressalta Batista:

"As relações entre grupos distintos é mais que um compartilhamento material, também é visto como um teor altamente simbólico. De acordo com Marcel Mauss (2003) a reciprocidade pode ser a retribuição de um presente, de um favor ou, nas relações de interação social, pode ser ilustrada com a atenção à fala do outro, com demonstrações de interesse e afeto, que são práticas capazes de estabelecer e manter convivências" (Batista 2011:14). 
Ainda sobre as matérias primas, no período de chuva a produção fica comprometida, de certa forma. Tanto na associação, como nas residências das mulheres, há escassez da matéria-prima em razão do aumento do volume das águas dos rios e igarapés, lugares próprios para a coleta da matéria prima dos artefatos. Na grande estiagem que o estado sofreu no ano de 2015, por exemplo, a produção de sementes também foi quase nula nas matas que cercam as margens do rio Branco, por conta das intensas queimadas nos campos e florestas. Assim, a associação recorreu a compra de sementes e miçangas em centros artesanais, em lojas de material para bijuterias ou de outros povos indígenas, para continuar a produzir e vender o artesanato.

Depois de produzido, o artesanato é comercializado em lugares que as mulheres encontram oportunidade para vender, como eventos acadêmicos e culturais promovidos pelas instituições de ensino superior, como a UFRR - Universidade Federal de Roraima, por organizações indígenas, entre elas o Conselho Indígena de Roraima - CIR; além de outros eventos voltados para a temática indígena que ocorrem em Boa Vista e nas cidades vizinhas. A associação também é sempre convidada a fazer performances da dança parixara e de defumação com o maruai ${ }^{3}$.

\section{O quesito estético}

Os artefatos indígenas, como já apontamos, não partilham da mesma noção de arte comum a sociedade nacional. Além disso, o senso comum percebe as manifestações artísticas indígenas como algo singular, como uma "arte comum e geral dos índios" (Velthem 2010:57), porém há uma grande diversidade de povos que se expressam artisticamente de várias formas, nos mais variados contextos, com produções significados diferentes, como afirma Delci: "[...] nós Wapichana fazemos artesanato diferente dos Ingarikó né[...]”. Na Kapói, os povos Wapichana, Macuxi e Patamona representam essa diversidade cultural que é respeitada e todos conhecem um pouco da cultura de cada um por meio das peças artesanais, da alimentação, conhecimentos de plantas medicinais, entre outros. 
Os artefatos indígenas ainda se revestem de particularidades, "materializando redes de interações complexas, considerando laços, ações, emoções, significados e sentidos" (Lagrou 2005:70), além das funções representativas e utilitárias. Percebendo essas concepções, se observa que "a valorização estética de um artefato indígena pode não estar contida no próprio objeto, mas se afirma ao exprimir uma relação, pois estaria condensada na própria utilização do artefato ou em sua permuta" (Velthem 2010:59).

A utilização de matérias primas específicas é imprescindível na confecção dos artefatos, pois "a qualidade estética também pode ser encontrada na adequação dos elementos" (Velthem 2010:59). Dessa forma, Velthem explica que as produções artísticas expressam, na vida indígena, os conhecimentos acerca das matérias primas empregados, das técnicas de confecção e do simbolismo agregado, e que a qualidade estética está presente na adequação de elementos, onde o uso de matérias primas específicas é muito importante para que dado artefato adquira forma e função.

Certa ocasião, o presidente da associação comentou que quando falta material, os associados propõem substituir algumas matérias primas, como fibras da palha de buriti e arumã, por cipó de goiabeira para fazer cesto, o que ele não recomenda, pois prefere utilizar matéria prima apropriada ou 'material de verdade'; ainda segundo ele, a qualidade do cipó de goiabeira é ruim e não é o material apropriado para fazer cestos. É necessário utilizar a matéria prima adequada para cada peça e assim produzir artesanato de qualidade e de acordo com que foi aprendido na comunidade. As mulheres utilizam diversas sementes na produção de peças artesanais, sendo que as mais comuns são encontradas na floresta ou nos centros que comercializam sementes para bijuterias, entre as quais estão:

- Morototó (Schefflera morototoni)

- Olho de boi (Talisia esculenta)

- Saboneteira (Sapindus saponária)

- Paxiúba (Socratea exorrhiza) 
- Jarina (Phytelephas macrocarpa)

- Buriti (Mauritia flexuosa)

- Tucum (Astrocarym huaimi)

- Coquinho (Astrocaryum aculeatum)

- Açaí (Euterpe oleracea)

Além das sementes, palhas e fibras também são bastante usados na produção de cestos e abanos, como fibra de buriti, fibra de arumã, fibra e palha de tucumã - matérias primas adequadas para os trançados e imprescindíveis na confecção dos artefatos. Tais peças ou objetos que são de uso cotidiano nas comunidades, são reproduzidos na cidade tanto para uso doméstico das mulheres, como para fins comerciais. Em suas viagens pela região de savanas e florestas de Roraima, entre 1911 e 1913, Koch-Grünberg, destaca a diversidade do artesanato indígena.

"Os trançados, em contrapartida, que são monopólio dos homens [...] fornecem os produtos mais variados: esteiras de folha de palmeira, abanos trançados, cestinhos cilíndricos de diferentes formas e tamanhos, apás para guardar beiju, tipitis para prensar a massa de mandioca, pequenas canastras para guardar tabaco, miçangas e outras bugigangas" (Koch-Grünberg 2006:60).

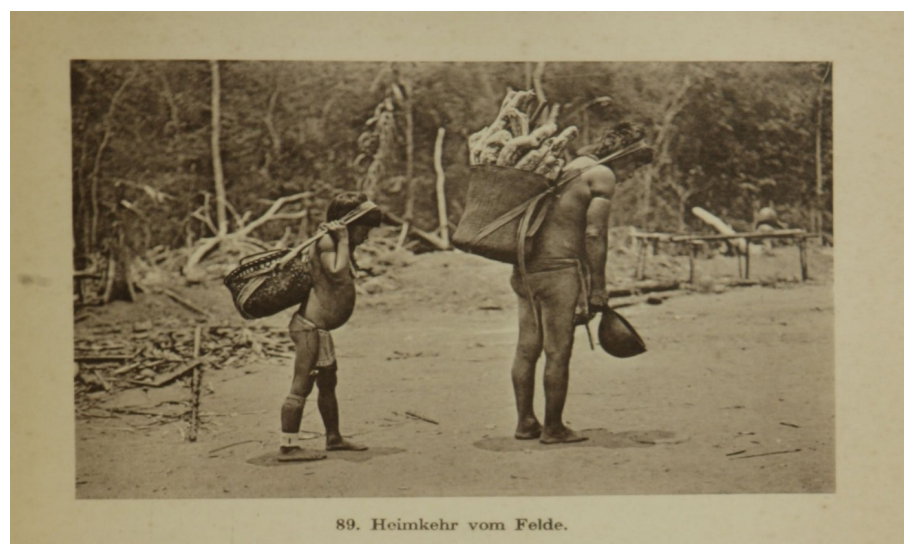

Figura - 2: Registro de Koch -Grünberg onde se vê cestos no uso cotidiano de indígenas da região de campos e serras. Fonte: Koch-Grünberg. Vom Roraima zum Orinoco (Volume 1, 1917). 
As peças que as mulheres confeccionam necessitam de um certo controle de qualidade para serem vendidas, ao mesmo tempo evidenciam a destreza da artesã, com todo cuidado de fazer 'bem-feitinho' cada artefato para não descaracterizar o seu valor tanto estético quanto econômico. Existe todo um cuidado e paciência para não arruinar o artefato que está em processo de confecção, assim de maneira minuciosa, destreza, e é claro, dedicação, as mulheres produzem peças de grande beleza estética: colares com diversas sementes, brincos de penas, enfeites de cabelo, cestos de fibra com decoração, abanos, entre outras.
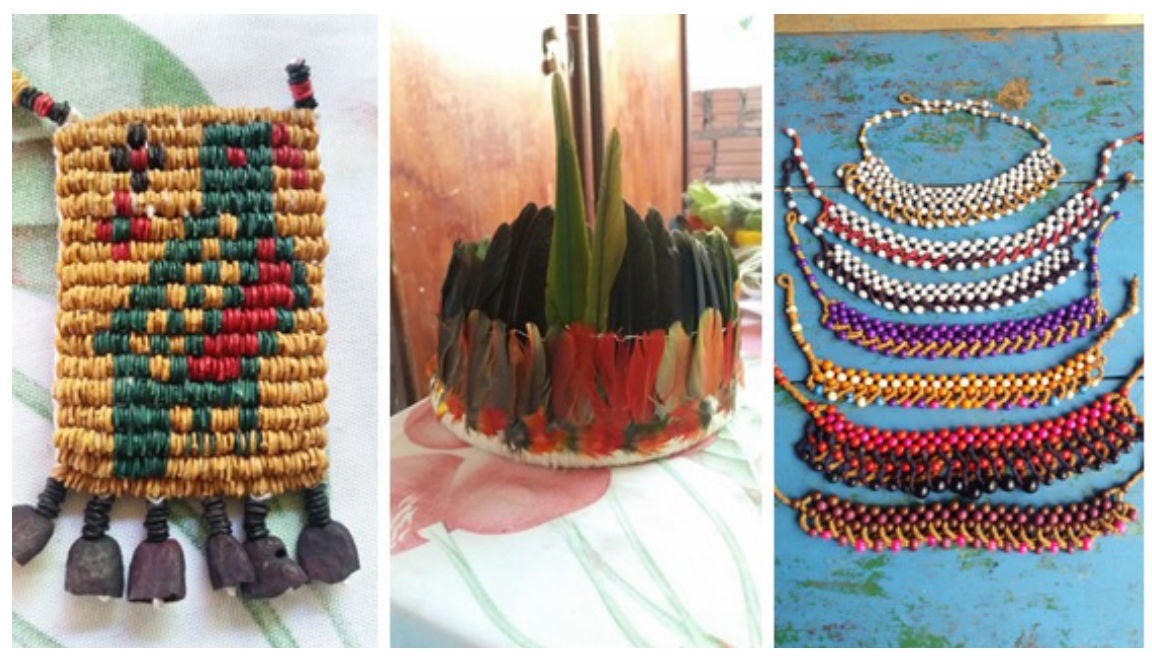

Figura - 3: Colar de semente de morototó com desenho de papagaio, cocar de penas de papagaio e colares de sementes diversas. Fonte: Martes, 2016.

Nas visitas feitas pela pesquisadora à associação, as mulheres a ensinavam a fazer alguns colares e brincos, trabalho este não foi bemfeito. Logo depois as mulheres refizeram as peças para ficarem 'bemfeitinhas' e assim vender por um preço bom. Dona Maria confirma essa destreza de fazer 'bem-feitinha' e o porquê: “[...] tem que fazer direitinho também, se fizer mal-feita aí ninguém vai querer comprar porque tu faz mal, tem que fazer bem arrumadinho, bem bonito [...] 
Eu acho muito bom ver as pessoas usando as coisas que eu fiz". A perfeição da peça é importante para atrair a atenção e reconhecimento dos consumidores.

O fazer 'bem-feitinho' significa que a beleza e a estética do artefato produzido chamará atenção de possíveis compradores, ou seja, os detalhes são imprescindíveis na produção, além de ser também questão de prestigio, como destaca o relato de Dona Maria, quando encontra pessoas usando peças que ela mesma fez, indicando para outras colegas “essa pessoa comprou isso de mim!" e completa:

A tia Selestina falava: bora aprender Maria. [...] eu não sei amarrar, aí ela me ensina: segura assim! Aí que eu amarrei arrumadinho. Eu sei fazer colar, sei fazer brinco, pulseira, aprendi fazer cesto também. Eu faço em casa, de vez em quando eu venho ajudar ela aqui também, a gente vende pra associação e a gente passa quarta e sábado aqui. (Maria).

Delci relata que ao desenvolver as atividades artesanais na associação teve a oportunidade de conhecer peças artesanais de outras etnias, participando de eventos e encontros, e sempre que via uma peça diferente, comprava para tentar reproduzir em casa por mera curiosidade, mas apesar disto, ela procura manter em suas peças as formas e modelos que aprendeu com Dona Selestina e Dona Vanda. Ao contrário das mulheres Ye 'kuana que fazem questão de incorporar novas técnicas e desenhos de outros povos, nas peças produzidas em miçanga (Paes 2018), para elas trata-se de enriquecimento cultural.

As mulheres que confeccionam os artefatos na Kapói, que designam aquelas peças como artesanato, em geral não observam esses objetos como artísticos, incorporado no conceito de "arte ocidental", mas sim como reproduções de um conhecimento adquirido por terceiros e de forma coletiva, com concepções estéticas nos seus próprios termos. Como apontado acima, a concepção de arte indígena não se encaixa na concepção de arte na sociedade nacional; ao contrário, os artefatos indígenas carregam o estilo artístico próprio de cada povo. 
Dona Vanda, por exemplo, se apresenta como artesã. Relata que vem de uma família de artesãos e leva muito a sério sua profissão por estar reproduzindo o conhecimento adquirido no contexto familiar, que não apenas representa sua cultura, mas principalmente serve para afirmação de identidade no contexto urbano. Ela é a pessoa que mais encoraja as mulheres a persistirem no trabalho que fazem no âmbito da associação, sua experiência frente as organizações indígenas e na produção artesanal são motivacionais no âmbito da Kapói. Diferentemente de Dona Vanda, Dona Maria não se vê como tal: "eu não acho que sou artesã, só faço o que tô acostumada a fazer”, e diz que faz artesanato porque gosta de fazer mesmo, além de ser uma atividade que ela faz tanto na associação quanto em casa, conta ela que gosta porque é bom trabalhar pra si mesma, além de indicar que é uma pratica prazerosa, como também ressalta Dona Clara sobre as oficinas semanais realizadas para confeccionar o artesanato: "Estou adorando muito essas oficinas, ainda mais de ser uma participante nessa associação [...]".

A atividade artesanal entre as mulheres também estabelece uma espécie de conexão entre passado e presente relativa aos conhecimentos técnicos que elas dominam, "[...] muitos povos indígenas consideram que parte de seu conhecimento é coletivo e foi recebido de terceiros - inimigos, outros povos, seres ancestrais" (Goldestein 2014:13), situando também a importância da conservação do saber 'tradicional'.

\section{O saber ancestral no universo urbano}

"O artesanato constitui-se uma prática fundamental no processo de aprendizado e educativo de grupos sociais. O processo de aprendizagem por parte de um artesão ocorre geralmente através da transmissão de conhecimento e informações de pais aos filhos, que, por sua vez, aprenderam com seus pais e avós, transmitindo de geração a geração, todos responsáveis pela tradição e inovação do produto que ao mesmo tempo é identidade, arte, lazer, trabalho, profissão e subsistência" (Amaral 2010:63).

Os indígenas que residem na cidade conciliam seus saberes tradicionais com os novos saberes ou conhecimentos adquiridos no con- 
tato, e é desta forma que as mulheres da Kapói procuram viver nesse novo contexto. Apesar de suas peças sofrerem interferência de outras culturas, as vezes para agradar os clientes, quase sempre certos, que pedem de outros modelos ou cores, as peças 'tradicionais' sempre estão presentes, pois como intérpretes de suas culturas, visualmente os artefatos produzidos mantêm a identidade dos povos que a criaram, mas também é importante frisar que o saber tradicional é dinâmico, por isso existe a possibilidade da incorporação de novos elementos.

Cavalcante (2013), apontou como as panelas Macuxi foram se transformando quando atingiram o universo urbano. Os compradores sugeriam que as 'tradicionais' panelas pudessem ter uma tampa, traziam panelas de casa, como sugestão de modelo para as mulheres diversificarem sua produção. Com o passar do tempo e para atender as demandas dos consumidores, as mulheres passaram a produzir panelas com tampas, panelas de tamanhos e formatos diversos surgiram as assadeiras, de formato quadrado, em forma de coração, entre outros.

O local onde funciona a associação, que também é a casa de Dona Selestina, é um ponto de referência da produção e venda do artesanato, ao mesmo tempo se configura como um lugar de construção de redes de relações, onde os visitantes são bem recebidos e estabelecem relações com os produtores do artesanato, como ela mesma constata. Logo, é em suas próprias residências que as mulheres prezam pela continuidade de sua cultura - por meio dos ensinamentos aos seus filhos, a língua materna, as comidas típicas, como a damurida ${ }^{4}$, e a produção de artefatos.

A produção artesanal exprime uma realidade material de uma cultura cuja importância desse tipo de manifestação cultural traduz a afirmação de sujeitos e o valor simbólico no contexto urbano, além de representar uma coletividade, onde acredita-se que a conservação da tradição se dá pela transmissão do conhecimento de geração à geração. Delci agora está passando seus conhecimentos para suas filhas mais velhas, ela considera importante que seus filhos aprendam e 
mantenham alguns aspectos do universo cultural ao qual ela foi criada, e afirma:

Eu quero ensinar tudo que eu sei pra eles (filhos), porque eles tão crescendo e eu tô ficando velhinha, e eu não vou ficar fazendo as coisas pra eles não. Tem que aprender fazer colar, plantar roça, falar Wapichana e inglês porque assim eles vão poder ir lá na comunidade conhecer os parentes deles né. (Delci).

Dona Clara conta que gosta muito do que aprende na associação, antes ela não sabia fazer colar, brincos e outros objetos porque só sabia cuidar da casa e fazer trabalho doméstico. Quando conheceu a associação, através de uma amiga, se interessou em aprender porque aquilo fazia parte de sua cultura e achou importante. Hoje ela faz todo tipo de artesanato, ainda com auxílio de Dona Selestina para que nada saia errado.

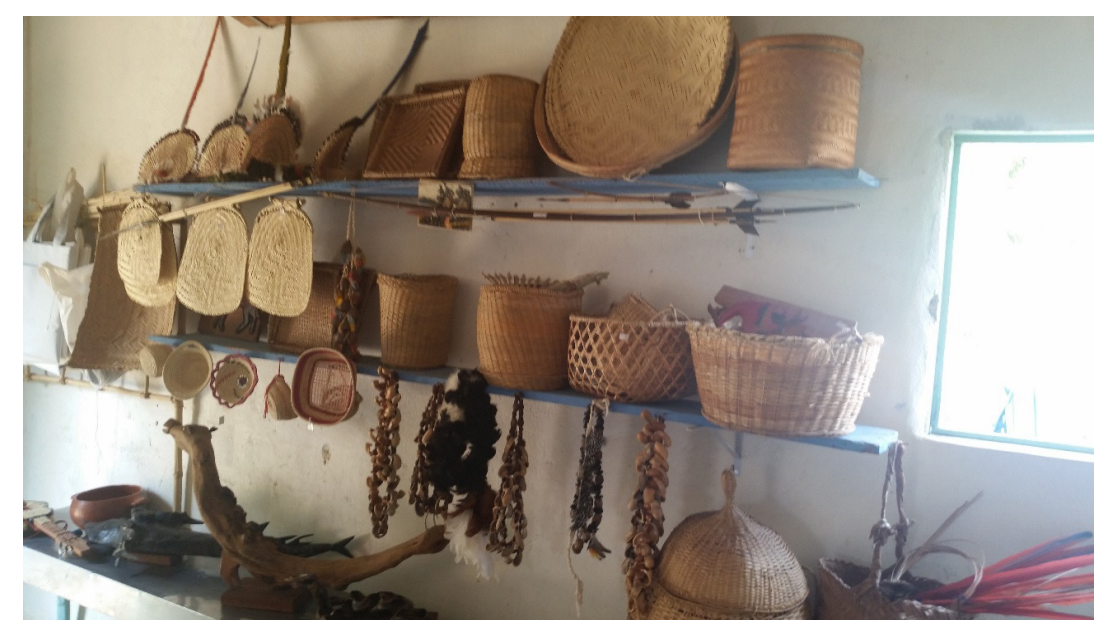

Figura - 4: Cestos, abanos e outros artefatos feitos de trançados. Fonte: Martes, 2016.

Na produção artesanal na Kapói, cabe aos homens furar as sementes com furadeiras, confeccionar as cestarias, além de talharem madeira para fazer esculturas. Culturalmente a divisão de trabalho sexual 
existe na confecção de artefatos indígenas, e apesar de a confecção de trançados, que emprega matérias-primas vegetais, constituir uma atividade essencialmente masculina para os povos das terras baixas da América do Sul, na Kapói as mulheres se articularam para aprenderem também a trançar e assim produzir cestaria, diferentemente dos homens que não se interessaram em aprender a confeccionar peças feitas com sementes, como colares, brincos, pulseiras e outros. Segundo Velthem (2007), entre os povos indígenas das terras baixas da América do Sul, a produção de trançados carrega um conjunto de conhecimentos e saberes que variam de um povo indígena para outro, e na associação Kapói as mulheres se propuseram a aprender as técnicas de trançado para também produzir e conservar tal conhecimento.

Dona Vanda comenta que brincava fazendo cestos e que agora domina muito bem essa atividade, e assim ela ensina outras mulheres a fazer cesto e outros artefatos de fibra e palha. Diante desse contexto, as articulações de gênero sofrem transformações sociais e culturais na estratégia de luta e sobrevivência na cidade. Além disso, algumas mulheres, as mais velhas, ainda fiam algodão para confeccionar redes. Tal atividade é longa, principalmente na comunidade, que vai desde a plantação do algodão, colheita até a confecção e produção final da rede, assim Delci cita: "[...] na comunidade a gente planta [...]. Com algodão a gente faz de tudo, faz tipoia, faz rede, faz cocar”.

A produção de panelas de barro pelas mulheres Macuxi, principalmente nas comunidades, é bem famoso no estado de Roraima, mas o trabalho com sementes também é bastante presente. Dona Vanda, apesar de afirmar que vem de uma família de artesãos, diz que a única atividade que não teve oportunidade de aprender foi a produção de panelas de barro. No período de contato nas comunidades indígenas Macuxi, a inserção da panela de alumínio, no qual o cozimento dos alimentos é mais rápido, impactou a produção das panelas de barro, que ficou restrita às mulheres mais velhas, que guardaram os conhecimentos relativos a essa atividade (Cavalcante 2013). Hoje, além das sementes, Dona Vanda trabalha muito com miçangas e fibras, ela tam- 
bém reserva um espaço em sua casa onde guarda todo o material que consegue de amigos e o que ela mesma coleta em suas andanças. Dona Vanda, talvez seja o exemplo mais bem sucedido, entre as mulheres da associação, ele diversificou suas atividades, indo além da produção das peças produzidas no âmbito da associação. Tem um bom trânsito entre instituições de ensino, como a Universidade Federal de Roraima, faz constantes viagens a Guiana, de onde traz a matéria prima e alguns artefatos lá adquiridos para vender em Boa Vista.

A produção artesanal indígena é diversa e rica, como observamos, tanto pelas matérias primas utilizada quanto pelas habilidades técnicas empregadas, do qual os objetos são produzidos e que exprimem diferentes formas de conhecimento e significados, e também por evidenciar a realidade vivida por aqueles que destinam seu tempo a confeccioná-las, conjugando visão, gesto e contexto social como instrumentos de aprendizado.

As habilidades técnicas utilizadas na produção de um artefato indígena são conhecimentos ancestrais transmitidos de uma geração a outra, e isso é um fator importante dentro da estrutura social de vários povos indígenas. De acordo com Velthem (2014), tais criações e habilidades técnicas de uma pessoa são fundamentais para sua inserção no meio social e seus efeitos contribuem para a harmonia da vida familiar e comunitária.

No contexto da Kapói, a circulação de conhecimento ancestral indígena é bastante visível: os Macuxi, Wapichana e Patamona, trocam saberes entre si e os transmitem às crianças, além da língua, que é um ponto forte como diacrítico indígena, e dentro disso as mulheres também utilizam a estratégia do 'saber fazer' na manutenção da cultura na cidade.

Entre os povos indígenas são considerados mestres aqueles detentores de certos conhecimentos e experiência de vida, geralmente os mais velhos; é responsabilidade deles passar tal saber aos mais novos para preservar o conhecimento cultural às futuras gerações. A transmissão do saber fazer ocorre tanto de forma oral quanto visual, nes- 
se último caso, observar o outro constitui uma técnica de aprendizado importante. As mulheres indígenas da Kapói, por meio da produção de artefatos, demostram a continuidade da sua cultura no universo urbano. Nesse sentido, suas manifestações culturais se aproximam da definição de cultura em Geertz (2008) como um ato ou um conjunto de atos simbólicos compartilhados num contexto público, que podem ser encontrados nos artefatos e estados de consciência. Assim ele esclarece:

“[...] Como sistemas entrelaçados de signos interpretáveis (o que eu chamaria símbolos, ignorando as utilizações provinciais), a cultura não é um poder, algo ao qual podem ser atribuídos casualmente os acontecimentos sociais, os comportamentos, as instituições ou os processos; ela é um contexto, algo dentro do qual eles podem ser descritos de forma inteligível - isto é, descritos com densidade" (Geertz 2008:10).

Quando falam sobre a sua cultura, as mulheres da Kapói deixam transparecer essa visão semiótica de cultura, algo contextual, como relata Delci: "Minha 'cultura' é saber fazer o que eu aprendi desde pequena, plantar, cantar, falar minha língua materna, pra gente não perder, desaparecer né?”. Assim ela percebe seu contexto cultural por meio das práticas cotidianas que aprendeu desde criança e que é necessário manter, tanto na comunidade quanto na cidade, para que não se perca.

O termo cultura, segundo Cunha (2009), é emprestado pelo indígena para destacar sua 'cultura' numa lógica de sistema distinta, proveniente de uma definição tanto individual, de visão de mundo, quanto compartilhada, pensado na coletividade. Sendo assim, o conceito de 'cultura' - entre aspas - é evidenciado como recurso de afirmação étnica diante de Estados nacionais, ou seja, opera num regime de etnicidade, diferente do que a sociedade ocidental encara o conceito de cultura num termo generalizado e público, que é invisível e obvio, porém, ambos termos coexistem, produzindo efeitos específicos.

A associação Kapói, em particular as mulheres, articulam essas atividades culturais como diacrítico de grupos sociais dos quais fazem 
parte, procurando se expressar culturalmente na cidade, construindo autonomia e noção de pertencimento por meio do artesanato, da dança, da culinária, enfim, por meio de seus conhecimentos tradicionais.

\section{Considerações finais}

Este trabalho procurou evidenciar a experiência das mulheres indígenas no contexto da cidade de Boa Vista, enfatizando suas estratégias de sobrevivência e afirmação cultural por meio da produção de artesanato. Nesse contexto, observou-se ainda processos de transformações nas relações de gênero e novas formas de protagonismo feminino, mostrando que as mulheres indígenas, cada vez mais, vêm ocupando espaços públicos, em organizações e associações direcionadas a pensar e propor ações voltadas para a melhoria das suas condições de vida e de suas famílias.

Nesse sentido, ser mulher indígena é, antes de tudo, promover a continuidade dos saberes antigos e ao mesmo tempo lutar contra as desigualdades específicas de seu gênero. Ainda, mas não menos importante, essas transformações assumem um avanço significativo no campo de resistência e luta, além de provar que um saber coletivo, o artesanato indígena, pode ser um instrumento de visibilidade e legitimação da presença indígena em Boa Vista. Aqui, como na comunidade, a técnica e a destreza na produção das peças, se relaciona a ideia de perfectibilidade presente entre inúmeros povos indígenas das terras baixas sul-americanas. Além disso, a comercialização destes artefatos, feitos em coletivos construídos no espaço urbano, se torna um complemento de renda e autonomia para essas mulheres.

\section{Notas:}

1 O termo Kapói provem da língua Macuxi - família linguística Caribe - que significa lua, símbolo escolhido para representar a associação. Os Macuxi, Wapichana e Patamona são os povos indígenas que integram a associação. As mulheres aqui 
citadas são as senhoras Selestina (Wapichana, 56 anos), Delci (Wapichana, 33 anos), Maria (Wapichana, 41 anos), Clara (Wapichana, 48 anos) e Vanda (Macuxi, 58 anos).

2 Confeccionar determinados objetos, entre os povos indígenas nas terras baixas da Amarica do Sul, significa que a pessoa reuni as habilidades necessárias para se casar e constituir família. Por exemplo, entre os Wapichana, é apreciado como bom conjugue a mulher que sabe fazer rede de algodão e o homem que sabe fazer trançado.

3 Resina extraída de uma árvore.

4 Caldo picante feito a partir da carne moqueada, podendo ser peixe, carne de caça ou outras carnes.

\section{Referências:}

PORTO ALEGRE, Maria Sylvia. 1998. "Imagem e representação do índio no século XIX”. In GRUPIONI, Luís D. (ed.): Índios no Brasil, pp. 59-72. São Paulo: Global. Brasília: MEC.

AMARAL, Assunção. 2010. "Artesanato Quilombola: identidade e etnicidade na Amazônia". Cadernos de CEOM, 23(1):61-75.

ARONI, B. O. 2010. "Por uma etnologia dos artefatos: arte cosmológica, conceitos mitológicos". PROA Revista De Antropologia E Arte, 1(2). (https:// www.ifch.unicamp.br/ojs/index.php/proa/article/view/2376; Acesso em: 07/06/2016).

BATISTA, Cristina. 2011. A produção artesanal Tapeba: relações entre construção material e imaterial de um povo. XI Congresso Luso Afro-Brasileiro de Ciências Sociais. Salvador-BA.

CAVALCANTE, Olendina. 1997. Migração e Gênero: Mulheres indigenas em Manaus. Monografia de Especialização. Manaus: Universidade do Amazonas. 2013. "Gênero e agência feminina Makuxi". Textos E̊ Debates,18:93-111.

CUNHA, Manuela C. 2009. Cultura com aspas e outros ensaios. São Paulo: Editora Cosac Naify.

FLORISSI, S. \& FIOTETTI, E. 2012. "Roraima na rede: caminhos alternativos tecidos por produtores e articuladores culturais". In LOUREIRO, J., OLIVEIRA, R. \& DUARTE, R. (eds.): Arte e cultura na Amazônia: os novos caminhos, pp. 131-145. Boa Vista: Editora da UFRR.

FONSECA, Claudia. 2003. "De afinidades a coalizões: uma reflexão sobre a 'transpolinização' entre gênero e parentesco em décadas recentes da antropologia". Revista Ilha, 5(2):05-31.

GEERTZ, Clifford. 2008. A interpretação das Culturas. Rio de Janeiro: LTC. 
GOLDSTEIN, I. S. 2014. "Artes indígenas, patrimônio cultural e mercado". PROA Revista De Antropologia E Arte, 1(5). (https://www.ifch.unicamp.br/ojs/index. $\mathrm{php} / \mathrm{proa} /$ article/view/2331; Acesso em: 07/06/2016).

KOCH-GRÜNBERG, Theodor. 2006. Do Roraima ao Orinoco: observações de uma viagem pelo norte do Brasil e pela Venezuela durante os anos de 1911 a 1913. São Paulo: Editora UNESP.

LEMOS, Maria Edny S. 2011. O artesanato como alternativa de trabalho e renda: Subsídios para Avaliação do Programa Estadual de Desenvolvimento do Artesanato no Município de Aquiraz-CE. Dissertação de Mestrado. Fortaleza: Universidade Federal do Ceará.

LAGROU, E. 2010. "Arte ou artefato? Agência e significado nas artes indígenas". PROA Revista De Antropologia E Arte, 1(2). (https://www. ifch.unicamp.br/ojs/index.php/proa/article/view/2385; Acesso em: 07/06/2016).

McCALLUM, Cecília. 1999. "A aquisição de gênero e habilidades produtivas: o caso Kaxinawá". Estudos Feministas, 7(1-2):157-175.

MELO, Luciana. 2013. "A formação sociocultural de Boa Vista - Roraima e os povos Macuxi e Wapichana da cidade: processos históricos e sentidos de pertencimento". Textos $\mathcal{E}$ Debates, 23:115-133.

. 2014. Populações Indígenas na Cidade de Boa Vista - Roraima: Dinâmicas Sociais e processos de (re)significação identitária em contexto urbano. Trabalho apresentado na 29a Reunião Brasileira de Antropologia. NatalRN.

OVERING, J. 1991. "A estética da produção: o senso de comunidade entre os Cubeo e os Piaroa". Revista de Antropologia, 34:7-33.

PAES, Dayana. 2018. Arte indígena: miçangas na cultura Ye'kuana. Dissertação de Mestrado. Boa Vista: Universidade Federal de Roraima.

RIBEIRO, B. \& VELTHEN, L. 1992. "Coleções etnográficas: documentos materiais para a história indígena e a etnologia”. In CUNHA, M. C. (ed.): História dos indios no Brasil, pp.103-111. São Paulo. Companhia das Letras.

SACCHI, A \& GRAMKOW, M. M. 2010. Gênero e povos indígenas: coletânea de textos produzidos para o 'Fazendo Gênero 9' e para a '27a Reunião Brasileira de Antropologia'. Rio de Janeiro/ Brasília: Museu do Índio/ GIZ FUNAI.

VELTHEM, L. H. 1998. "Arte indígena: referentes sociais e cosmológicos". In GRUPIONI, Luís D. (ed.): Índios no Brasil, pp.83-92. São Paulo/Brasília: Global/MEC. 2009. "Mulheres de cera, argila e arumã". Mana, 15(1):213-136.

. 2010." Artes indígenas. Notas sobre a lógica dos corpos e dos artefatos". Textos Escolhidos de Cultura e Artes Populares, 7:54-65.

. 2014. "Serpentes de Arumã. Fabricação e estética entre os Wayana (Wajana) na Amazônia Oriental”. PROA Revista De Antropologia E Arte, 1(5). (https://www.ifch.unicamp.br/ojs/index.php/proa/article/view/2338.; Acesso em: 07/06/2016). 

cultural affirmation of indigenous women in Boa Vista/RR

\begin{abstract}
The present work results from research carried out with indigenous women, members of the Kapói Indigenous Cultural Association, who left their communities of origin in Guyana, and today reside in the urban context of the city of Boa Vista, capital of Roraima, where they use indigenous art crafts as an instrument of income generation and cultural affirmation. The production of art craft highlights the techniques and knowledge apprehended in community life and the criteria of doing well, common to other indigenous peoples of the South American lowlands, and necessary for the new social universe that values an aesthetically wellmade product for sale.
\end{abstract}

Keywords: Indigenous art craft, Indigenous women, Urban context, Cultural difference.

Recebido em abril de 2021. Aprovado em outubro de 2021. 